\title{
Lid lengthening by sclera interposition for eyelid retraction in Graves' ophthalmopathy
}

\author{
Maarten Ph Mourits, Leo Koornneef
}

\begin{abstract}
The efficacy of scleral grafts for eyelid lengthening in patients with thyroid related upper and/or lower lid retraction was evaluated in 62 consecutive patients with Graves' ophthalmopathy who underwent lid surgery in the last 3.5 years. Seventy-eight upper and 30 lower lids were lengthened by scleral interposition. A good or acceptable result was achieved in $50 \%$ of all operated upper lids after one procedure. This percentage increased to $\mathbf{7 5 \%}$ after a second and to $77 \%$ after a third procedure. Persistent temporal retraction and nasal overcorrection were the major complications. In lower lid lengthening the success percentage was $90 \%$ after one operation. We conclude that scleral grafting for upper eyelid lengthening has no distinct advantage in comparison with other lengthening techniques. Scleral implants to lengthen lower lids are very effective.
\end{abstract}

Even after successful treatment with corticosteroids or orbital irradiation many patients with Graves' ophthalmopathy need surgical repair for rehabilitation. This may yield excellent results provided surgery is deferred till ocular and orbital symptoms have become stable. ${ }^{1}$ Disfiguring proptosis can be treated by orbital decompression, while the field of binocular single vision can be restored by extraocular muscle surgery..$^{23}$ Eyelid lengthening with or without dermatochalasis correction is usually the final step of surgical rehabilitation.

Many different techniques have been described to lengthen eyelids in Graves' ophthalmopathy. In 1979 Callahan and Callahan stated that recession of the eyelid retractors is best achieved with scleral grafts. ${ }^{4}$ Indeed the use of sclera for lower lid lengthening has been generally accepted. However, there is disagreement about its use in the treatment of thyroid related upper lid retraction. For this condition sclera has been advocated by some, ${ }^{56}$ while its efficacy has been questioned by others. ${ }^{7-9}$ Unfortunately, sufficient data on surgical outcome are lacking in most of these studies.

We report on a large series of consecutive patients in whom sclera has been used for both upper and lower lid lengthening. The outcome of our treatment method is compared with that of other methods.

\section{Patients and methods}

From January 1986 till July 198962 consecutive patients with thyroid related eyelid retraction underwent lid lengthening by scleral interposition at the Orbital Centre of Amsterdam.
Table 1 Patient's characteristics

\begin{tabular}{|c|c|c|}
\hline & $\begin{array}{l}\text { Upper lid } \\
\text { lengthening }\end{array}$ & $\begin{array}{l}\text { Lower lid } \\
\text { lengthening }\end{array}$ \\
\hline $\begin{array}{l}\text { No. of patients } \\
\text { No. of eyelids } \\
\text { Female/male ratio } \\
\text { Mean age and range (yr): M }\end{array}$ & $\begin{array}{l}47 \\
78 \\
4: 1 \\
47(26-64) \\
55(48-68)\end{array}$ & $\begin{array}{l}22 \\
30 \\
2: 1 \\
48(29-60) \\
56(42-68)\end{array}$ \\
\hline
\end{tabular}

Seventy-eight upper and 30 lower lids were corrected. Information on the patients is summarised in Table 1.

The diagnosis of Graves' ophthalmopathy was based on clinical signs and symptoms and coronal CT scans of the orbit. All patients were euthyroid and had stable eye disease for at least half a year prior to lid surgery. Many patients had been treated with immunosuppressive treatment, radiotherapy, orbital decompression, and extraocular muscle surgery.

The indication for surgical correction was cosmesis in all patients, but the majority complained of ocular discomfort as well, and luxation of the globe was imminent in two.

Preoperative evaluation consisted in measurements of palpebral fissure and scleral show in the primary position of gaze at 12 and 6 o'clock, lid margin to lid crease distance definition, and exophthalmometer readings. Pre- and postoperative photographs were taken of all patients.

The outcome of surgery was evaluated after three months. Second and third procedures were performed if no cosmetically acceptable result had been achieved. The final cosmetic result was evaluated by the patients and the surgeons. Upper lid correction was considered to be good if (1) the upper 1.5 to $2.0 \mathrm{~mm}$ of the cornea at the 12 o'clock position was covered by the lid; (2) the lid margin contour was smooth; (3) the lid crease was within 7 to $10 \mathrm{~mm}$ of the lid margin; and (4) there was bilateral symmetry (Figs 1 and $2 \mathrm{~A}, \mathrm{~B}$ ). An acceptable result was considered to be 1 to 2 mm over or under correction or mild asymmetry, requiring no further surgery (Figs $3 \mathrm{~A}, \mathrm{~B}$ ). If the lid margin of the lower lid touched the limbus at the 6 o'clock position and the contour was smooth, lower lid correction was considered to be good (Figs 4A, B). When there was a gap between the lid and the limbus of no more than $1 \mathrm{~mm}$, it was considered acceptable.

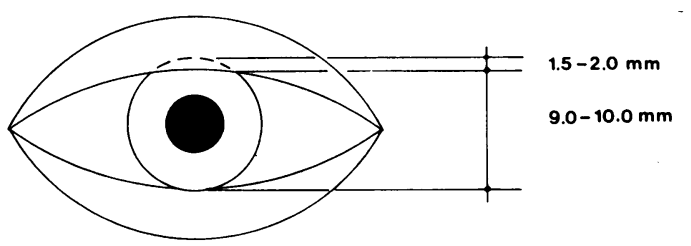

Figure 1 Drawing showing contour and position of eyelids in ideal situation. 
Figure 2 Pre-and postoperative appearance of a patient with unilateral upper eyelid retraction. Good result.

Figure 3 Pre-and postoperative appearance of a patient with unilateral upper gelid retraction. Slight asymmetry, acceptable result.

Figure 4 Pre-and postoperative appearance of a patient with unilateral, a patient with unilater
left-sided lower lid retraction. Good result.

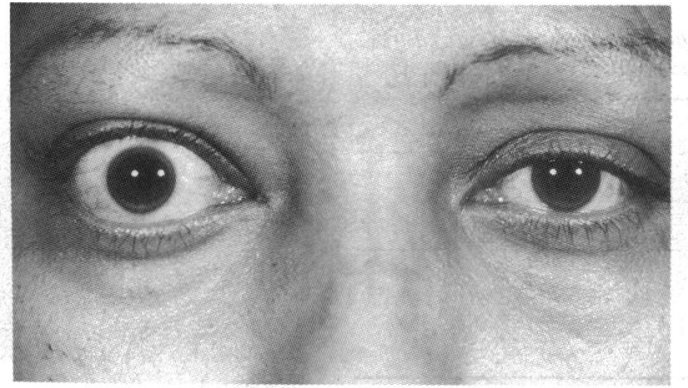

Figure 2A.

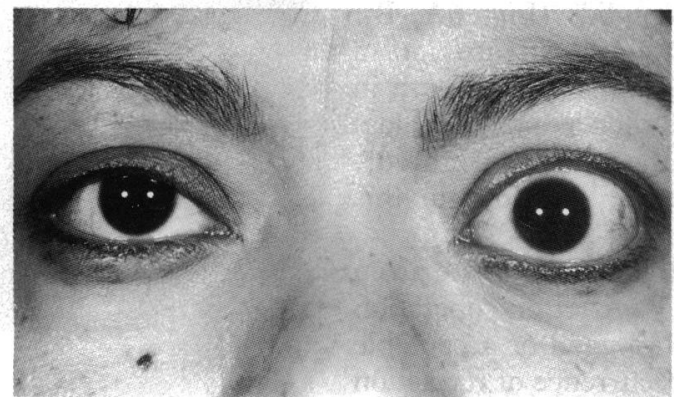

Figure 3A.

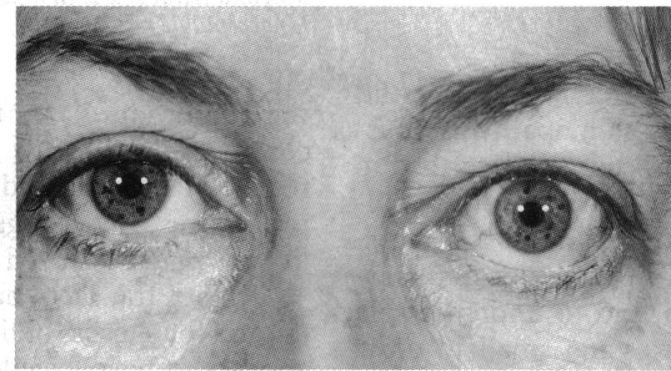

Figure $4 A$.

SURGICAL TECHNIQUE

The approach is much as described for ptosis surgery previously. ${ }^{10} \mathrm{~A}$ horizontal line is drawn on the eyelid at about $7 \mathrm{~mm}$ from the lid margin to mark the place of the future skin crease. After eversion of the superior eyelid, $2 \mathrm{ml}$ of lignocaine $2 \%$ with epinephrine is injected into the subconjunctival area. Thus the conjunctiva is separated from Müller's muscle. The upper eyelid is then further anaesthetised subcutaneously with approximately $3 \mathrm{ml}$ of local anaesthetic. A horizontal incision in the skin crease is made through the skin-muscle layer parallel to the muscle fibres on to the tarsal plate. By going upward in the direction of the upper roof of the orbit the orbital septum is visualised. The septum is opened, the orbital fat is freed, and below the fat the levator aponeurosis is identified. The levator aponeurosis together with Müller's muscle are dissected off the tarsal plate, and the medial and lateral horns are transected. The conjunctiva, however, is left unimpaired, thus protecting the cornea. Special care is taken to cut all fibrotic strands in the lacrimal gland region. A scleral graft is sutured to the tarsal plate and the levator muscle with interrupted 5.0 Vicryl sutures. In upper lids the vertical height of the implant is approximately twice the amount of eyelid retraction, laterally some millimetres more than medially. However, the final determination of the levator recession and thus of the graft size is based on the operation table appearance of the lid margin. For

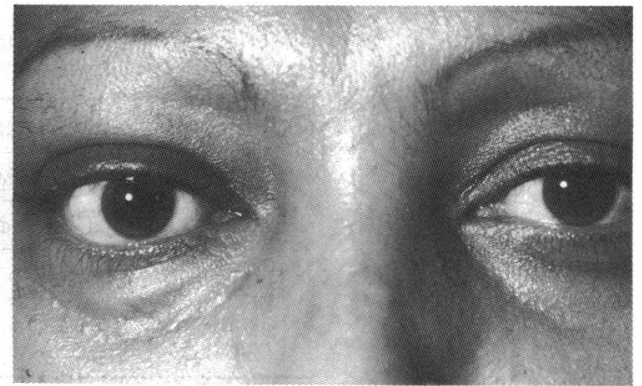

Figure $2 B$.

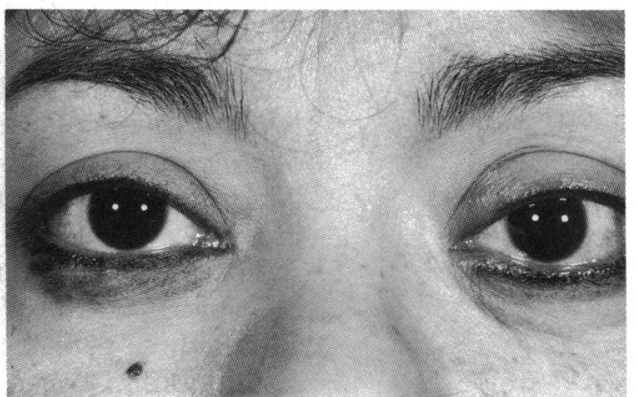

Figure $3 B$.

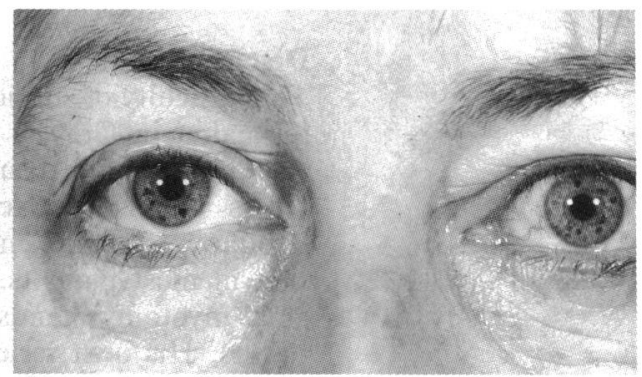

Figure 4B.

these assessments the patient is asked to open and close his eyes. When the result is satisfactory, the skin is closed with 6.0 silk sutures.

In second and third procedures the eyelid is opened up through the former scar. The scleral implant is dissected free and adjusted or replaced.

In lower lids the approach is transconjunctival. After infiltration of the subconjunctival space with local anaesthetic the conjunctiva is incised over the lower border of the tarsal plate. The lower lid retractors are identified and dissected off the conjunctiva and the tarsus and freed of the orbital septum. A scleral graft of about three times the lid retraction in millimetres is sutured to the retractors and the tarsal plate with $5 \cdot 0$ Vycril. The conjunctiva is closed with a running 6. 0 catgut suture.

\section{Results}

The outcome of surgery was evaluated at a fixed interval three months postoperatively. Followup varied from 0.5 to 3.5 years. The results of upper lid lengthening are given in Table 2 and Fig 5. Less retraction postoperatively was seen in all patients, and ocular discomfort disappeared in all but two. The cosmetic result was good or acceptable in $50 \%$ after one procedure and in $77 \%$ after a maximum of three procedures. Final evaluation showed mild or severe overcorrection or medial dropping in seven lids and temporal 
Table 2 Final outcome of upper lid lengthening procedures by sclera implantation for thyroid related eyelid retraction

\begin{tabular}{|c|c|c|c|c|c|}
\hline \multirow{3}{*}{$\begin{array}{l}\text { Amount of } \\
\text { retraction }\end{array}$} & \multirow[b]{3}{*}{ Number } & \multicolumn{4}{|c|}{ Result } \\
\hline & & \multicolumn{3}{|c|}{ Success } & \multirow[b]{2}{*}{ Failure } \\
\hline & & Good & Acceptable & Total & \\
\hline $\begin{array}{l}1-3 \mathrm{~mm} \\
4-5 \mathrm{~mm} \\
6-10 \mathrm{~mm} \\
1-10 \mathrm{~mm}\end{array}$ & $\begin{array}{l}25 \\
36 \\
17 \\
78\end{array}$ & $\begin{array}{l}20 \% \\
33 \% \\
18 \% \\
26 \%\end{array}$ & $\begin{array}{l}52 \% \\
53 \% \\
47 \% \\
51 \%\end{array}$ & $\begin{array}{l}72 \% \\
86 \% \\
65 \% \\
77 \%\end{array}$ & $\begin{array}{l}28 \% \\
14 \% \\
35 \% \\
23 \%\end{array}$ \\
\hline
\end{tabular}

obliquity in another seven lids (Figs 6A, B). Asymmetry was seen in four patients, and a thickened eyelid for longer than one month in two. Other complications such as a dry eye, loss of lashes, or extrusion of the graft did not occur. No recurrence of retraction was seen in this group.

The results of lower lid lengthening are given in Table 3 and Figs 7A, B. After one operation all but three patients had a good or acceptable result. Within a year, a recurrence of retraction was noted in two patients.

\section{Discussion}

The difficulty of surgical correction of upper lid retraction in Graves' ophthalmopathy is illustrated by the numerous procedures described to recess the lid retractors. Henderson's müllerotomy is insufficient to obtain enough recession in most patients. ${ }^{91}$ Groves's levator marginal myotomy ${ }^{12}$ tends to lead to unpredictable results. His own series was too small to draw conclusions from. Several other techniques ${ }^{13-15}$ have not been analysed in large enough numbers to demonstrate a high rate of success.

We have used scleral grafts to lengthen upper and lower lids in patients with Graves' ophthalmopathy because we expected more predictable and favourable results. After one procedure, however, only $50 \%$ of all operated upper lids were satisfactory. It has been suggested that scleral grafts cause lid thickening, cysts, and corneal damage, ${ }^{16}$ but in our patients (medial) overcorrection and/or obliquity of the lid edge as a result of persistent temporal retraction were the most important complications. Meticulous dissection of the lateral part of the levator aponeurosis could not prevent this. To avoid persistent temporal retraction we have used grafts that were so tapered they were wider temporally than medially, as suggested by Dryden and Soll. ${ }^{5}$ In spite of this, temporal retraction was noted even after a second and

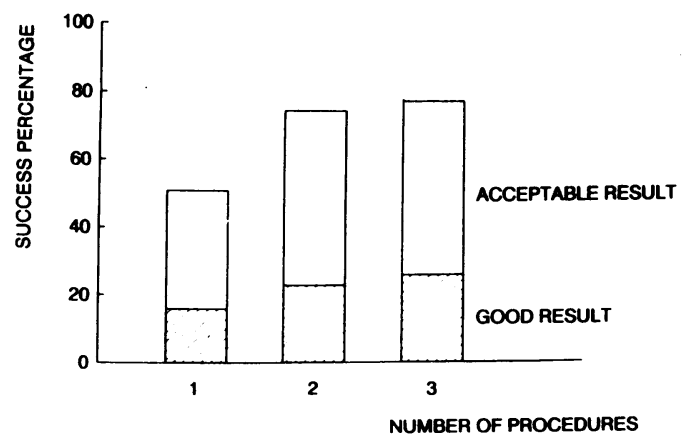

Figure 5 Diagram showing success percentage of upper lid lengthening in relation to number of procedures.

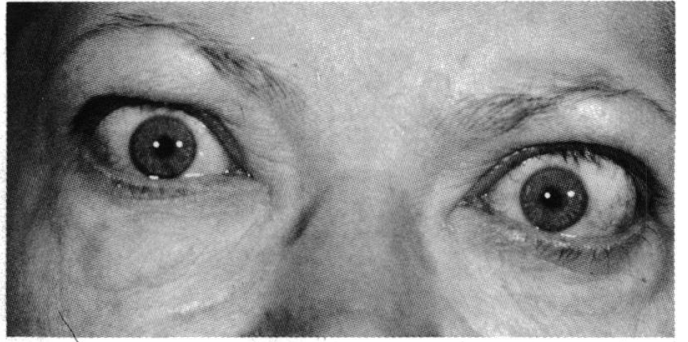

Figure 6A.

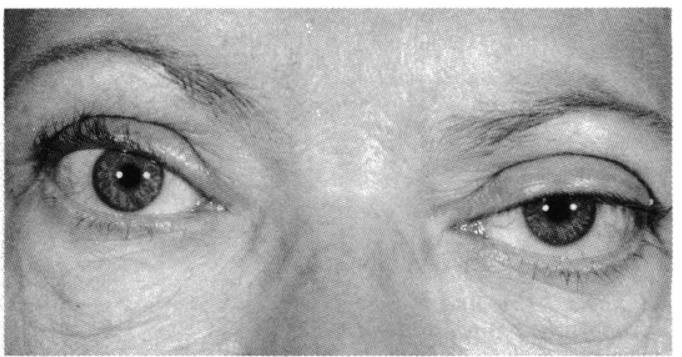

Figure $6 B$.

Figure 6 Pre-and postoperative appearance of a patient with bilateral upper eyelid retraction. Typical persistent temporal retraction with resulting oblique lid edge. Unacceptable result.

third procedure. In these patients we found considerable fibrosis in the lacrimal gland region, which tended to recur after repeated procedures. We suggest that this excessive fibrosis may be caused by the scleral implant.

Despite the fact that Putterman defined his criteria for success of lid surgery in less detail, he appears to have excellent results from a graded Müller's muscle excision and levator recession without the use of sclera: $80 \%$ of his 32 patients had a satisfactory result after one intervention. ${ }^{717}$ Thaller et al also reported good results in twothirds of 30 patients after levator recession without the use of sclera. Levator recession with scleral graft in their hands was less predictable.'

Although it is impossible to make a statistical comparison between their procedures and our method, these reports and our experience with scleral grafts indicate that sclera does not in-

Table 3 Final outcome of lower lid lengthening procedures by sclera implantation for thyroid related eyelid retraction

\begin{tabular}{|c|c|c|c|c|}
\hline \multirow[b]{3}{*}{ Number } & \multicolumn{4}{|l|}{ Result } \\
\hline & \multicolumn{3}{|c|}{ Success } & \multirow[b]{2}{*}{ Failure } \\
\hline & $\overline{\text { Good }}$ & Acceptable & Total & \\
\hline 30 & $63 \%$ & $34 \%$ & $97 \%$ & $3 \%$ \\
\hline
\end{tabular}

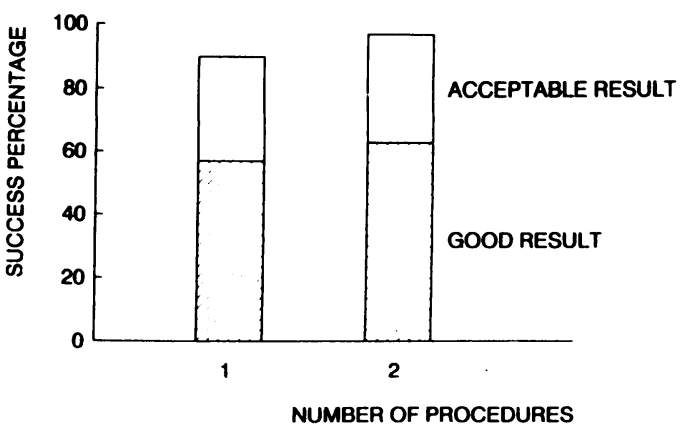

Figure 7 Diagram showing success percentage of lower lid lengthening in relation to number of procedures. 
crease the success rate of upper lid lengthening. On the other hand, our data do not prove that lid lengthening with sclera yields less acceptable results. We believe that, until it has been demonstrated that the more difficult procedure has a higher success rate, the simpler method should be the one of choice. For this reason we do not recommend scleral grafts for upper lid lengthening in Graves' ophthalmopathy.

Sclera for lower lid lengthening, on the contrary, is known to support the lid as a semi-stiff spacer against gravity.' This might explain our satisfactory results in lower lid surgery.

1 Mourits MP, Koornneef L, Wiersinga WM, Prummel MF, Berghout A, van der Gaag $R$. Clinical criteria for the assessment of disease activity in Graves' ophthalmopathy: a novel approach. Br f Ophthalmol 1989; 73: 639-44.

2 Mourits MP, Koornneef L, Wiersinga WM, Prummel MF, Berghout A, van der Gaag R. Orbital decompression for Graves' ophthalmopathy by inferomedial, by inferomedial plus lateral, and by coronal approach. Ophthalmology 1990; 97: 636-41.

3 Mourits MP, Koornneef L, van Mourik-Noordenbos, et al. Extraocular muscle surgery for Graves' ophthalmopathy. Extraocular muscle surgery for Graves' ophthalmopathy. Does prior treatment influe
Brf Ophthalmol 1990; 74: 481-3.
4 Callahan MA, Callahan A. Surgery for endocrine ophthalmopathy. In: Callahan MA, Callahan A, eds. Ophthalmic plastic pathy. In: Callahan MA, Callahan A, eds. Ophthalmic ple
and orbital surgery. Alabama: Aesculapius, 1979: 146.

and orbital surgery. Alabama: Aesculapius, 1979: 146.
5 Dryden RM, Soll DB. The use of scleral transplantation in cicatricial entropion and eyelid retraction. Ophthalmology 1977: 83: OP669-78.

6 Doxanas MT, Dryden RM. The use of sclera in the treatment of dysthyroid eyelid retraction. Ophthalmology 1981; 88: 887-94.

7 Putterman AM. Surgical treatment of thyroid-related upper eyelid retraction. Graded Müller's muscle excision and levator recession. Ophthalmology 1981; 88: 507-12.

8 Waller RR, Samples JR, Yeatts RP. Eyelid malpositions in Graves' ophthalmopathy. In: Gorman CA, et al, eds. The eye and orbit in thyroid disease. New York: Raven, 1984: 263-99.

9 Thaller VT, Kaden K, Lane CM, et al. Thyroid lid surgery. Eye 1987; 1: 609-14.

10 Hylkema HA, Koornneef L. Treatment of ptosis by levator resection with adjustable sutures via the anterior approach.
restoris BrF Ophthalmol 1989; 73: 416-8.

11 Henderson JW. Relief of eyelid retraction. Arch Ophthalmol 1965; 74: 205-16.

12 Grove AS. Upper eyelid retraction: treatment by levator marginal myotomy. Orbit 1982; 1: 21-31.

3 Schimek RA. Surgical management of ocular complications of Graves' disease. Arch Ophthalmol 1972; 87: 655-64.

14 Baylis HI, Cies WA, Kamin DF. Correction of upper eyelid retraction. Am F Ophthalmol 1976; 82: 790-4.

15 Beyer-Machule CK. Surgical treatment of thyroid-related eyelid retraction. Int Ophthalmol Clin 1989; 29:232-6.

16 Harvey JT, Anderson RL. The aponeurotic approach to eyelid retraction. Ophthalmology 1981; 88: 513-24.

17 Putterman AM, Urist $M$. Surgical treatment of upper eyelid Putterman AM, Urist M. Surgical treatment
retraction Arch Ophthalmol 1972; 87: 401-5. 